\title{
PERMASALAHAN PEREMPUAN DALAM NOVEL ISINGA KARYA DOROTHEA ROSA HERLIANY (KAJIAN FEMINIS)
}

\author{
Sally Rosalia Munster \\ Universitas Pattimura \\ e-mail: munstersally@gmail.com
}

\begin{abstract}
Abstrak: Permasalahan Perempuan dalam Novel Isinga karya Dorothea Rosa Herliany kajian feminis. Penelitian ini dilakukan karena peneliti tertarik terhadap permasalahan perempuan dalam novel Isinga. Dari permasalahan perempuan peneliti menggunakan kajian feminis. Manfaat penelitian ini secara teoretis dapat memberikan sumbangsih pikiran pemikiran terhadap pengembangan ilmu sastra, khususnya dapat bermanfaat untuk memperkaya penggunaan teori-teori sastra secara teknik analisis terhadap karya sastra. Secara praktis, penelitian ini dapat dimanfaatkan bagi pembaca terlebih khusus bagi dosen, guru Bahasa Indonesia dan mahasiswa Pendidikan Bahasa dan Sastra Indonesia. Penelitian ini menggunakan metode penelitian kualitatif. Data dalam penelitian ini adalah teks novel, ungkapan dan kalimat yang menunjuk pada permasalahan perempuan dalam novel Isinga karya Dorothea Rosa Herliany. Sedangkan sumber data dalam penelitian ini adalah novel Isinga karya Dorothea Rosa Herliany. Teknik pengumpulan data yang dipakai yaitu teknik kepustakaan dan teknik mencatat. Teknik analisis data yang dilakukan dalam penelitian ini adalah membaca novel Isingakarya Dorothea Rosa Herliany, mengidentifikasi dan mengklasifikasikan data, mencatat semua hasil identifikasi dan klasifikasi data dan menarik kesimpulan. Untuk pengecekan keabsahan data, peneliti menggunakan triangulasi teori. Berdasarkan data yang dihasilkan selama penelitian ini dilakukan, ditemukan ideologis feminis; permasalahan perempuan berupa ketidakadilan dan kekerasan terhadap perempuan; perjuangan perempuan antara lain perempuan yang tabah menghadapi kehidupan, perempuan yang mandiri dan perempuan yang berpikir maju; serta feminis radikal dalam novel Isinga.
\end{abstract}

Kata Kunci: Permasalahan Perempuan, novel, Isinga, Kajian Feminisme 


\title{
THE WOMAN PROBLEMS IN ISINGA NOVEL CREATED BY DOROTHEA ROSA HERLIANY AT FEMINISM RESEARCH
}

\author{
Sally Rosalia Munster \\ Pattimura University \\ e-mail: munstersally@gmail.com
}

\begin{abstract}
The Woman Problems in Isinga novel created by Dorothea Rosa HerlianyAt Feminism Research. This research was occurred because of the researcher's interesting for the woman problems. The research using feminism studies. The benefit of this research in theoretical is to give intelligence contribution for development of literature study its especially is useful for the literature theory in analysis technique of literature.This research is used qualitative research method. The data in this research is use novel text expression and sentence is refer to the woman problems in Isinga novel by Dorothea Rosa Herliany. While the data source in this research is Isinga novel by Dorothea Rosa Herliany. The technique of data accumulation which use is bibliography and record technique. Technique of data analysis in this research is reading Isinga novel by Dorothea Rosa Herliany, identification and classification the data, to note all identification and classification result, and make conclusion. For checking validation of data the researcher use triangulation theory.Based on result on the data in this research there are found feminism ideology of the woman problems; Such as justice and violence to woman; woman struggles likes the woman who stronger to confront the life, the woman who independently and the woman who though progressive with radical feminism in Isinga novel.
\end{abstract}

Keywords: Woman Problems, novel, Isinga, Feminism Research 


\section{A. PENDAHULUAN}

Karya sastra lahir ditengah masyarakat sebagai hasil imajinasi pengarang serta refleksinya terhadap gejala-gejala sosial disekitarnya, sehingga berfungsi sebagai potret-potret kehidupan melalui karakter yang diperankan dalam suatu karya sastra. Hanya saja penyampaiannya, pengarang sering mengemasnya dengan gaya yang berbeda-beda bagi kehidupan manusia, baik itu drama, cerpen maupun novel. Novel merupakan fiksi yang mengungkapkan cerita tentang kehidupan tokoh dengan problematika dan nilainilainya untuk mencari nilai otentik dalam dunianya. Menurut The Advanced Learner's Dictionary of Current English, novel adalah suatu cerita dengan suatu alur, cukup panjang mengisi suatu buku atau lebih, yang menggarap kehidupan pria dan wanita yang bersifat imajinatif (Tarigan, 1991:164).

Tujuan feminisme adalah meningkatkankedudukan dan derajat perempuan agar samaatau sejajar dengan kedudukan serta derajatlaki-laki. Perjuangan untuk mencapai tujuanini mencakup beberapa cara, termasukmelalui bidang sastra.Karya sastra yang bernuansa feminisdengan sendirinya akan bergerak padaemansipasi. Peneliti tertarik untuk mengkaji novel Isinga karya Dorothea Rosa Herliany. Hal ini dikarenakan adanya tokoh Irewa yang ditampilkan secara apik oleh pengarang.

Dalam novel ini digambarkan sosok perempuan yang begitu tabah menjalani hidup, padahal begitu banyak masalah yang menghiasi hidupnya.Berdasarkan uraian di atas maka peneliti memilih kajian feminis dikarenakan permasalahan perempuan kerap terjadi pada kehidupan nyata dan peneliti memiliki hasrat ingin tahu, apakah penerapan permasalahan perempuan pada novel tersebut dapat dianalisis dengan teori feminisme radikal. Berdasarkan rumusan masalah di atas, tujuan penelitian ini yaitu mendeskripsikan permasalahan perempuan dalam novel Isinga karya Dorothea Rosa Herliany.

\section{B. METODE PENELITIAN}

Metode penelitian yang tepat untuk novel Isinga karya Dorothea Rosa Herliany adalah metode kualitatif yang bersifat deskriptif. Dengan alasan pendekatan kualitatif merupakan prosedur penelitian yang menghasilkan data deskriptif berupa kata-kata tertulis.

Data dalam penelitian ini adalah data yang berupa teks novel, ungkapandan kalimat yang menunjukan pada permasalahan perempuan dalamnovel Isinga karya Dorothea Rosa Herliany.Sumber data dalam penelitian ini berupa novel Isinga karya DorotheaRosa Herliany. PT Gramedia Pustaka Utama, Jakarta 2015.Untuk mengumpulkan data, penulis menggunakan teknik kepustakaan danmencatat.Dalam penelitian ini digunakan analisis data menggunakan analisisdeskriptif.

Adapun prosedur analisis adalah sebagai berikut: (1) membacanovel Isinga karya Dorothea Rosa Herliany secarabaik; (2)mengidentifikasi dan mengklasifikasi data; (3) mencatat semua hasilidentifikasi dan klasifikasi data; (4) mengidentifikasi permasalahanperempuan dan (5) menarik kesimpulan.Dalam penelitian ini peneliti 
menggunakan triangulasi teori. Langkah yangpeneliti lakukan dengan triangulasi teori, yaitu membandingkan data yangdikumpulkan dengan beberapa teori yang relevan sehingga menemukan datayang akurat. Seperti membandingkan teori yang peneliti pakai dengan datayang dikumpulkan.

\section{PEMBAHASAN}

Pada bagian ini dipaparkan hasil penelitian yaitu permasalahan perempuan novel Isinga karya Dorothea Rosa Herliany. Deskripsi hasil penelitian tersebut disesuaikan dengan tujuan penelitian yaitu mendeskripsikan permasalahan perempuan dalam novel Isinga karya Dorothea Rosa Herliany dengan menggunakan kajian feminis.Berdasarkan hasil analisis data ditemukan beberapa permasalahan perempuan dalam novel Isinga karya Dorothea Rosa Herliany dan bentuk perjuangan yang dilakukan oleh tokoh perempuan dalam novel Isinga karya Dorothea Rosa Herliany. Permasalahan perempuan dan bentuk perjuangan tersebut antara lain yaitu:

\section{Permasalahan Perempuan dalam Novel Isinga}

Perempuan seringkali dihadapkan pada persoalan yang cukup rumit yang diakibatkan dari situasi hubungan laki-laki dengan perempuan yang tidak sejajar. Pola relasi ini mengakibatkan perempuan mendapatkan banyak ketidakadilan. Perempuan menanggapinya dengan berbagai cara dan sikap.

Permasalahan perempuan dapat dilihat pada tokoh Irewa dalam novel Isinga. Sebagaimana uraian berikut mengenai awal permasalahan perempuan dalam novel Isinga:

\footnotetext{
"Dengan pelan Mama Kame lalu memberitahu Irewa bahwa sudah

menjadi keputusan besar dua perkampungan ia harus kawin

dengan Malom. Mama Kame menjelaskan alasannya. Irewa menangis lagi. Ia ingin menjadi istri Meage yang dicintainya.

"Mama mengatakan perempuan bisa menolak laki-laki yang tidak ia cintai?"

"Benar begitu."

"Mengapa aku sekarang harus kawin dengan Malom?" "Karena ini keputusan dari semua rumah yowi di Aitubu

dan Hobone. Mereka yang memutuskan begitu. Jadi ini keputusan semua orang di Megafu," katanya."

"Kamu adalah satu-satunya jalan damai bagi permusuhan yang sudah bertahun-tahun terjadi, "Mama Kame menjelaskan lagi” (I :5252).
}

Dengan begitu Irewa yang tidak bisa menolak dan harus menerima dengan begitu saja untuk menikah dengan Malom harus terus menerima perlakuan yang tidak adil seperti kekerasan fisik bahkan Malom sama sekali tidak bertanggung jawab sebagai seorang kepala keluarga yang seharusnya bekerja untuk menafkahi keluarga. 


\section{a. Ketidakadilan terhadap Perempuan}

Ketidakadilan yang dialami tokoh perempuan dalam novel Isinga antara lain; ketidaksetaraan gender, kesenjangan sosial; dan sistem patriarki. Secara umum nasihat yang disampaikan masyarakat Aitubu dan masyarakat Hobone juga sama karena keduanya juga masih dalam satu wilayah yang ada di bawah Pegunungan Megafu. Begitu banyak nasihat yang diberikan kepada perempuan. Bahkan jika dicermati tugas dan peran laki-laki tidak seberat perempuan. Untuk menjadi laki-laki yang baikpun juga tidak serumit perempuan. Seperti dalam kutipan berikut:

"Seorang lelaki Iko sedang menjalankan sebuah tugas. Pegunungan raksasa Megafu meminta para laki-laki, orang kuat Iko menabur benih agar para perempuan menghasilkan anak. Keturunan untuk meneruskan sejarah. Anak laki-laki akan digunakan untuk menjadi prajurit Iko yang bertugas menjalankan perang. Mempertahankan sebuah keutuhan. Anak perempuan akan digunakan untuk merawat dan menjaga kelangsungan sebuah kehidupan. Rangkaian hidup yang akan terus berulang dan berputar. Semesta dilestarikan. Agar terus menerus ada seperti begitulah adanya" (I: 57)

Bahkan saat seorang istri tidak bisa melayani suami karena sedang mengalami kesakitanpun tidak dapat menolak ajakan suami untuk berhubungan. Seperti dalam kutipan ini :

"Irewa memaksakan diri melayani permintaan Malom. Tak tenang. Tegang. Kelaminnya terasa nyeri. Sakit. Irewa harus menghadapi apa saja yang terjadi atas dirinya. Begitulah juga yang dialami semua perempuan lain di bawah pegunungan Megafu. Mereka rata-rata mengalami hal sama. Harus terus- menerus melayani suami. Merawat anak jika nanti sudah lahir dan mengurus semua kebutuhan keluarga. Tak ada yang mengeluh.

Jadi Irewa juga tak ingin mengeluh. Para perempuan ini menjalani semuanya. Begitu saja. Mereka tidak mengenal kata adil dan tak adil. Mereka tak tahu, perempuan punya hak untuk menolak. Mereka hanya tahu bahwa memang begitulah sebuah kehidupan harus dijalani” (I : 70).

Sebagaimana dikutip bahwa laki-laki tugasnya adalah menabur benih, mengawini perempuan agar perempuan itu menghasilkan anak.Bagi perempuan Megafu, mengandung, melahirkan adalah peristiwa biasa yang telah dialami mereka beberapa kali. Hal tersebut dapat dilihat dalam kutipan berikut :

"Bagi perempuan Megafu, melahirkan adalah peristiwa biasa saja. Seperti peristiwa alam yang lain. Setiap perempuan akan melahirkan. Para perempuan Megafu tetap melakukan pekerjaan sehari-hari sampai kandungan mereka besar. Mereka tidak tahu kapan persisnya bayi akan lahir. Karena itu, banyak perempuan melahirkan 
ketika sedang di kebun. Ketika si perempuan sedang sendirian. Jauh dari pemukiman penduduk. Si perempuan tak bisa memanggil bantuan perempuan lain dari humia atau siapa saja. Persalinan dilakukan di tempat. Atapnya pohon. Dinginnya semak belukar. Alasnya rumput atau tanah coklat berdebu. Mungkin juga persalinannya di tempat lain. Di hutan. Di danau. Di pinggir sungai. Kalau itu terjadi mereka menanganinya sendiri" (I :71).

\section{b. Kekerasan terhadap Perempuan}

Perempuan Megafu juga bisa dikatakan sebagai perempuan yang tertindas. Bagaimana tidak? Kebebasan untuk memilih kehidupan yang seperti apa tidak didapatkan oleh mereka. Hal tersebut dapat dilihat dalam kutipan berikut :

"Kalau ada seorang suami memperlakukan istri dengan tidak baik, ada dua cara bagi perempuan Megafu untuk bisa lepas dari suaminya itu. Pertama, bunuh diri dengan terjun ke sungai besar dan deras. Ini banyak yang sudah melakukannya. Kedua, menunggu kalau ada laki-laki lain yang menyukainya. Tak bisa kalau keinginan datang dari perempuan" (I:74).

Mereka tidak punya banyak pilihan. Ketika suami memperlakukan istri dengan tidak baik mereka hanya ada dua pilihan yang berat. Bisa dikatakan hidup mereka seperti budak. Irewa mengalami semua itu dan dia hanya bisa pasrah menerima hidupnya. Seperti dalam kutipan berikut :

"Kalau sedang dipukul Malom, kadang-kadang Irewa teringat pada Lepi. Ia tak punya perasaan apa-apa padanya. Hanya saja, Irewa tahu Lepi suka padanya. Ia tahu, seorang perempuan bisa mendapatkan suami baru kalau ada laki-laki lain mau menjadi suaminya. Nanti akan ada hitung-hitungan tentang jumlah babi yang harus dibayarkan. Pihak calon suami kedua biasanya harus membeli perempuan sudah bersuami ini dengan babi yang jumlahnya banyak sekali. Sering pihak suami tidak mampu membayar jumlah yang banyak itu. Karena itu, jarang terjadi perempuan yang sudah kawin dan tidak suka dengan suami pertama, bisa dengan mudah mendapatkan suami yang kedua” (I:74).

Lepi merupakan orang yang suka kepada Irewa, beberapa kali Irewa pergi ke kebun dan sungai Lepi mengikutinya. Lepi sampai menemui seorang dukun untuk meminta sihir cinta supayaia bisa mengambil hati Irewaagar Irewa dapat melupakan suaminya Malom kemudian mencintai Lepi. Namun, keinginan Lepi pun harus kandas karena ia tak mampu kalau harus membayar babi yang banyak.

"Tak ada perempuan Megafu memikirkan tentang pisah dari suami. Tak ada yang melakukanya. Dulu pada saat menikah, ada pemberian babi sebagai mas kawin. Mas kawin tak ubahnya tanda melakukan apa saja terhadap perempuan. Cerai tak dikenal dalam kebiasaan di 
pegunungan Megafu. Apa lagi kalau perempuan itu adalah yonime seperti Irewa.

Lama-lama Irewa jadi marah pada dirinya sendiri. Ia membiarkan batinnya melampiaskan perasaan marah yang memuncak. Ia mengeluarkan umpatannya pada Malom. Katanya dalam hati, laki-laki itu seperti anak kecil. Merangkak dengan dua tangan. Seperti seekor anjing. Ia merengek padaku. Ia memintaku jadi istrinya. Dusun Kapo. Di Lembah Piriom. Di situ tempat aku tinggal. Laki-laki itu datang tiap hari walau aku ludahi. Ia katakan ia mencintai aku. Kini aku selalu dipukulinya. Aku selalu harus mengerjakan semuanya. Aku telah menjadi budaknya.

Oh, budak?

Irewa jadi kaget sendiri dengan kata itu: budak. Mengingatkan tentang sesuatu yang berkaitan dengan keinginan.

Seorang budak tak bisa punya keinginan. Saat belum menikah, perempuan bisa punya keinginan. Dulu ia bisa. Dulu ia punya itu. Menolak atau menerima laki-laki yang menyatakan cinta padanya. Irewa lalu jadi terpikir untuk kembali memiliki keinginan sendiri. Kini ia ingin bunuh diri!” (I :140).

Kekerasan yang dilakukan Malom terhadap Irewa selalu dilakukan jika tidak ada makanan. Hal tersebut dapat dilihat pada kutipan berikut :

"Irewa jatuh sakit lagi. Ia tak bisa pergi ke ladang. Musim kemarau panjang. Betatas diladang juga sudah tak ada yang bisa diambil. Betatas yang ada dirumah sungguh harus dihemat. Orangorang Hobone semua kekurangan makan. Betatas dirumah Irewa hari itu sudah hanya tinggal sedikit saja. Anak- anak Irewa sudah menangis semua karena lapar. Irewa memberi mereka betatas matang. Ada sisa sedikit untuk dirinya sendiri. Irewa merasa harus makan karena harus mengerjakan hal lain walau sakit. Malom lapar. Betatas matang tak ada. Ikan tak ada. Malom marah dan memukul Irewa. Setelah itu pergi ke Mama Fos untuk meminta makan. Malamnya tidur di rumah yowi bersama para laki-laki” (I :80).

"Pada hari keempat, Irewa belum juga sembuh dari sakitnya. Malom mulai memarahainya. Irewa bilang, ia merasa tidak ada tenaga untuk bekerja. Malom mengatakan betatas harus selalu ada. Ia lapar. Babi-babi harus di beri makan. Irewa menjelaskan tentang sakitnya. Malom kesal. Irewa di anggap banyak bicara. Mulut Irewa yang sedang bicara itu ditamparnya. Malom bilang, besok Irewa harus sudah pergi ke kebun lagi” (I:73).

Malom juga merupakan laki-laki yang sangat kasar dan sangat emosional bahkan tidak bisa mengendalikan diri ketika sedang marah. Hal tersebut dapat dilihat pada kutipan berikut:

"Kedua manusia itu ditendang. Tenaga laki-laki. Perasaan marah. Tendangan Malom terasa sangat saki. Malom lalu memukuli kepala Lepi. Lepi tak bisa melakukan serangan balasan. Malom memukulnya sekali lagi dengan tenaga yang lebih kuat. Irewa sudah 
berdiri. Malom menempeleng kepala Irewa. Irewa jatuh dengan mudah. Malom menendang tubuh Irewa yang sudah terjatuh ke tanah. Perut Irewa diinjak dengan kedua kaki. Lalu lepi dipukul sekali lagi. Ditendang sekali lagi. Puas. Malom lalu pergi meninggalkan keduanya. Lepi dan Irewa sama sakit tak terkira. Hidung berdarah. Lecet-lecet. Rasa nyeri. Tulang-tulang terasa ada yang patah. Irewa merasa seperti akan pingsan"(I : 79).

Irewa juga tak bisa berbicara terlalu banyak, karena ketika Irewa berbicara walaupun untuk kebaikan selalu saja dianggap salah bahkan Irewa sampai dipukuli. Hal tersebut dapat dilihat pada kutipan berikut :

"Malom marah. Irewa sudah menduga Malom akan marah. Irewa menjawab, hamang nenaeisele emei roibuyae helemende yang artinya makanan tidak datang dengan sendirinya, tetapi harus diusahakan. Ini sebetulnya kata-kata biasa yang sering diucapkan para mama di Hobone untuk anaknya. Maksud kalimat itu untuk menyindir. Irewa sebenarnya tidak bermaksud melawan Malom. Ia tau apa yang akan dialaminya kalau melawan. Tapi memang ia ingin memberi sedikit teguran halus. Irewa melihat laki-laki lain di zaman sekarang mulai bekerja. Tidak diam saja seperti yang dilakukan Malom. Malom marah sekali mendapat sindiran itu. Dengan cepat Ia mendekat ke Irewa. Bibir Irewa ditampar keras. Setelah itu Irewa dipukuli. Saat tubuh Irewa jatuh, ia ditendang berkali-kali. Irewa tak sempat membalas atau mengelak karena Malom mendekat padanya dengan sangat cepat. Irewa tersungkur. Tubuhnya meringkuk di tanah. Kedua kakinya terlipat. Tangan kanan dan kiri menyilang di pundak. Menahan segala kesakitan. Seluruh tubuhnya nyeri" (I:138).

\section{Perjuangan Tokoh Perempuan dalam Novel Isinga}

Dalam bagian ini penulis ingin menjelaskan bagaimana perjuangan tokoh perempuan untuk memerangi ketidakadilan yang terjadi.Tema yang terdapat dalam novel Isinga adalah perjuangan seorang perempuan dalam menghadapi kerasnya hidup.Novel Isinga juga menceritakan tentang perempuan yang kehidupannya diwarnai dengan penderitaan yang dilakukan oleh suaminya dengan kekerasan dalam berumah tangga. Novel Isinga melukiskan watak tokoh Irewa sebagai seorang perempuan yang memiliki kesabaran, ketabahan, giat bekerja keras, mandiri dan berpikir maju dalam menghadapi kehidupan yang penuh dengan tantangan dan penderitaan. Dengan demikian penulis dapat mendeskripsikan tentang perjuangan yang dilakukan oleh tokoh perempuan dalam Novel Isinga untuk memerangi ketidakdilan, antara lain:

\section{a. Perempuan yang Tabah Menghadapi Kehidupan}

Perjuangan perempuan Pegunungan Megafu memanglah tidak ringan. Irewa sebagai tokoh utama dalam sikap perjuangan perempuan di tanah Megafu mewarnai kisah cerita Isinga. Irewa adalah wanita kuat, tangguh, pantang menyerah. Perjuangan Irewa bermula dari keadaan yang memaksanya untuk memilih pendamping hidup. Pada akhirnya dia tidak 
bisa memilih laki-laki yang ia cintai sebagai pendamping hidup. Hal itu dikarenakan dia telah dijadikan sebagai yonime, juru damai yang memaksanya untuk menikah dengan laki-laki yang tidak ia cintai. Dalam hal ini, dia tidak bisa memperjuangkan kebebasannya untuk memilih pendamping hidup. Seperti tergambar dalam kutipan berikut:

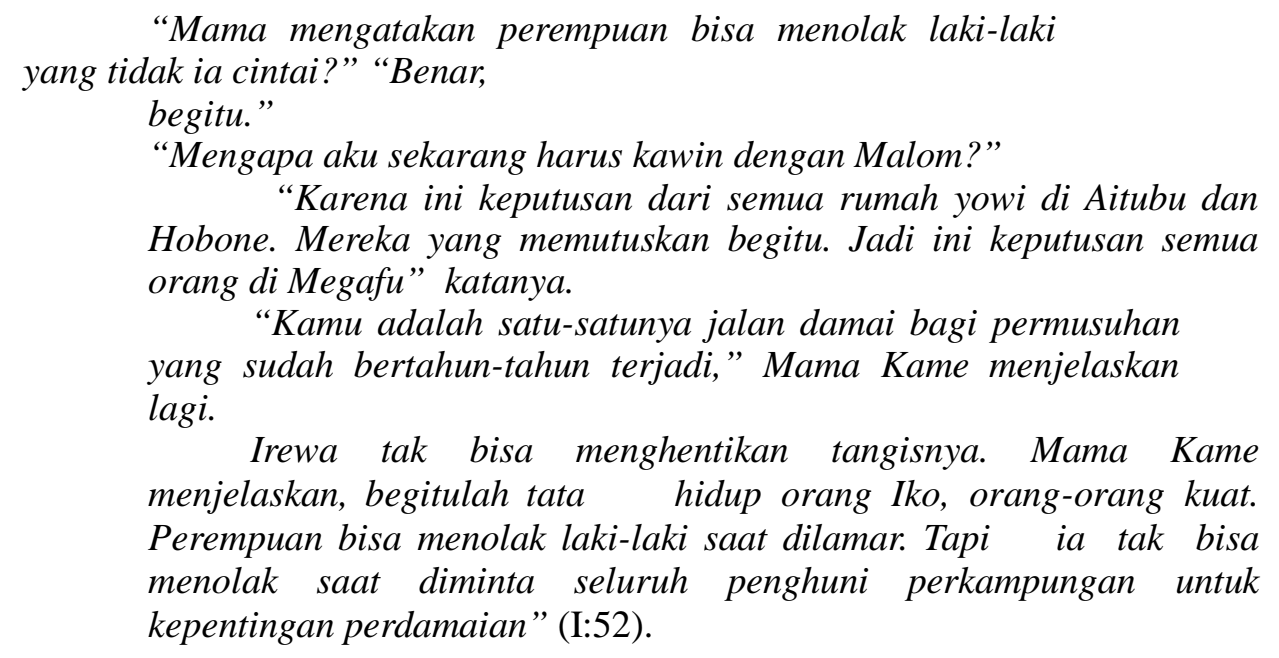

\section{b. Perempuan yang Mandiri}

Perempuan yang mandiri yang dimaksud adalah Saat perempuan hamil mereka harus bekerja mengurus semuanya, keluarga, hewan, tanaman, dan suami mereka dan tidak dibantu oleh suaminya. Seperti yang tergambar jelas saat Irewa hamil dia pun juga tetap harus bekerja seperti hari biasa. Bagi perempuan Megafu, mengandung, melahirkan adalah peristiwa biasa yang telah dialami mereka beberapa kali.

"Bagi perempuan Megafu, melahirkan adalah peristiwa biasa saja. Seperti peristiwa alam yang lain. Setiap perempuan akan melahirkan. Para perempuan Megafu tetap melakukan pekerjaan sehari-hari sampai kandungan mereka besar. Mereka tidak tahu kapan persisnya bayi akan lahir. Karena itu, banyak perempuan melahirkan ketika sedang di kebun. Ketika si perempuan sedang sendirian. Jauh dari pemukiman penduduk. Si perempuan tak bisa memanggil bantuan perempuan lain dari humia atau siapa saja. Persalinan dilakukan di tempat. Atapnya pohon. Dinginnya semak belukar. Alasnya rumput atau tanah coklat berdebu. Mungkin juga persalinannya di tempat lain. Di hutan. Di danau. Di pinggir sungai. Kalau itu terjadi mereka menanganinya sendiri" (I:71).

Perempuan Megafu telah terbiasa dengan peristiwa kelahiran. Mereka bisa melahirkan kapan pun dan di mana pun mereka berada jika waktunya tiba. Suami mereka tidak peduli dan tidak pula mau membantu persalinan istrinya. Hal yang menarik adalah ada rasa malu jika perempuan tidak bisa melakukan persalinan sendiri.

"Sudah seperti itulah perempuan Megafu. Dari sejak dahulu sampai sekarang. Para perempuan saling memberi tahu cara mengeluarkan bayi ke sesama perempuan. Para mama. Mama Fos. 
Mama tetangga. Perempuan sebaya. Mereka melakukan persalinan sendiri. Semua perempuan sudah tahu caranya. Perasaan takut tak ada. Ada rasa malu kalau tidak bisa melakukan persalinan sendiri” (I:72).

\section{c. Perempuan yang Berpikir Maju}

Perjuangan Irewa untuk menjadi perempuan baik Hobone hampir kandas di tengah jalan kerena niatnya bunuh diri. Segera ditepis niat itu, karena ia segera ingat tentang anak-anaknya yang sangat membutuhkan kehadirannya. Disitu terlihat bahwa Irewa merupakan perempuan yang berpikir maju dan mau untuk melakukan sesuatu yang lebih baik.

"Irewa melihat dirinya lagi. Lalu anak-anak. Tanggung jawab! Ah! Irewa sekarang memikirkan tentang tanggung jawab manusia. Kini timbang-menimbang antara keinginan dan tanggung jawab. Irewa lalu ingat pada anak-anaknya. Ia sangat menyayangi mereka. Ah, Irewa marah! Kini pada dirinya sendiri. Bagaimana mungkin ia tega meninggalkan anak-anaknya? Tidak, kata Irewa. Ia menolak keinginan kuat untuk bunuh diri. Irewa juga jadi ingat tentang hidupnya lagi. Ia merasa harus menghargai dirinya sendiri. Di Megafu perempuan sudah tak dihargai. Oleh karena itu, perempuan dihargai harus oleh perempuan itu sendiri. Tak bisa ia mengharapkan hal itu dari orang lain" (I:142).

Irewa mulai menyadari bahwa selama ini dia hanya memperjuangkan nasibnya sebagai perempuan. Perjuangan selanjutnya yang dilakukan Irewa adalah mengubah pandangan orang lain tentang hal perempuan dengan cara menceritakan pengalamannya saat terkena penyakit sifilis dan mengajak para perempuan pedagang untuk menjaga anak laki-lakinya agar tidak masuk dalam dunia pelacuran yang melanda wilayah yang Irewa tinggali.

"Irewa kini sudah lebih menyadari akan dirinya. Zaman dulu, yonime diminta menjaga keselarasan masyarakat di dua kampung. Irewa kini berfikir, ia tak mau terikat hanya pada dua kampung itu saja. Kebutuhan untuk waktu sekarang adalah, ia harus ikut memikirkan keharmonisan pada tempat di mana ia berada saat ini. Irewa merasa terpanggil untuk menjadi orang yang punya pengaruh mengubah pandangan orang lain" (I:157).

"Irewa mulai menyampaikan pendapatnya tentang pelacuran. Ia menceritakan pengalamannya saat terkena penyakit sifilis. Ia menceritakan walau perempuan hanya melakukan hubungan badan dengan suami saja, terkena penyakit kelamin. Ia juga mengajak para perempuan pedagang di pasar menjaga anak laki-lakinya hatihati” (I:157).

Irewa juga gencar mempengaruhi pemikiran para perempuan bahwa perempuan harus berani melawan laki-laki. Suami mereka yang selama ini telah memperlakukan perempuan-perempuan itu secara tidak baik harus dilawan. Keadilan untuk perempuan 
harus ditegakkan. Perempuan tidak selamanya menjadi budak. Perempuan harus bangkit dari ketertindasan kaum laki-laki. Perjuangan Irewa belum berakhir.

\begin{abstract}
"Irewa menceritakan, anaknya sendiri sudah dia jaga dengan baik, tapi pergaulan menyebabkan anaknya tetap terbawa masuk ke pelacuran. Masih banyak yang disampaikan Irewa. Irewa yang dulu sering melihat bagaimana kegiatan di

"sekolah setahun", kini jadi seperti seorang guru. Bicaranya mantap dan menarik bagi semua yang mendengarkan. Si perempuan dari Pulau Jawa itu ikut mendukung apa yang dikatakan Irewa bahwa perempuan harus berani melawan laki- laki. Perempuan lain yang selama ini telah diperlakukan tak baik oleh suami ikut mendukung. Semua jadi saling dukung-mendukung” (I:157,158).
\end{abstract}

Perjuangan Irewa terus berlanjut dengan melakukan kegiatan dalam bentuk memberikan pengetahuan dan berbagi pengalaman masalah perempuan pada perempuanperempuan di daerah pedalaman dengan dibantu oleh Jingi, saudara kembarnya dan Ibu Selvi, kepala desa di wilayah tempat tinggalnya.

"Irewa tetap meneruskan kegiatannya. Menjaga keharmonisan. Kini dibantu Jingi, ia memberikan pengetahuan pada perempuan di daerah-daerah pedalaman. Pengalaman yang disampaikannya pertama kali di pasar itu disampaikanya pula ke perempuan lain di tempat lain. Jingi menambahi penjelasan dari segi kesehatan. Jingi dan Irewa terus bergerak dari satu wilayah ke wilayah lain. Irewa mengatur waktunya mengerjakan itu saat semua pekerjaan di rumah sudah diselesaikan" (I:159).

"Irewa lalu menceritakan pengalamannya sendiri bahwa ia dulu juga pernah terkena penyakit sifilis. Sama dengan dirinya, banyak perempuan di pedalaman yang tak tahu-menahu soal penyakit itu. Lalu membiarkan saja. Tak tahu harus bagaimana. Diobati sendiri dengan cara yang diajarkan nenek moyang dulu. Tapi tidak sembuhsembuh. Mereka tidak tahu kalau harus berobat ke dokter. Lalu akhirnya meninggal dunia" (I:186)

Irewa sangat semangat berjuang memberikan pengetahuan dan berbagi pengalamannya. Jingi membantu memberi penjelasan dari segi kesehatan. Ibu Selvi selalu mendukungnya hingga memberinya sebuah tempat ruangan untuk berkumpul para perempuan-perempuan itu bersama Irewa.

"Ruang Marya adalah nama ruang yang baru dibangun di kantor distrik. Ibu selvi dan Irewa yang memberi nama itu setelah lama tak menemukan nama yang dirasa cocok. Marya dalam bahasa daerah berarti busur. Mereka berdua ingin agar ruang itu menjadi busur dan panahnya adalah para perempuan. Busur dan anak panah akan dipakai untuk membunuh hal-hal buruk. Hal-hal bodoh. Ibu selvi dan Irewa mengajak para perempuan membunuh 
hal-hal lama yang tak baik. Membunuh tangis karena hidup serba kekurangan. Tidak punya uang. Tak bisa makan. Membunuh kebiasaan buruk. Makan sayur tanpa dimasak dengan baik. Minum air yang tidak di masak. Membunuh kebiasaan kotor. Tidak menjaga kebersihan. Buang sampah sembarangan. Dan lain-lain. Seperti yang direncanakan, ruang itu juga dipakai membunuh hal-hal menyangkut kesehatan, anak, dan remaja pada sesama perempuan yang datang ke ruang itu. Jingi masih terus memberi Irewa informasi-informasi kesehatan kalau ada yang baru dan penting diketahui" (I : 193-194).

Perjuangan Irewa pun juga dilakukannya untuk saudara kembarnya, Jingi. Irewa berusaha membujuk Jingi agar mau menikah dengan Meage, lelaki yang dicintai Irewa. Irewa ikhlas mengorbankan perasaan cintanya kepada Meage untuk Jingi. Tak masalah bagi Irewa. Apalagi Irewa juga sudah bersuami Malom meskipun sikap Malom kepadanya buruk. Perjuangan hidupnya kini hanya untuk anak-anaknya dan para perempuan di daerahnya. Menyadarkan mereka untuk mendapatkan keadilan.

"Menikahlah kau dengannya, Jingi, "kata Irewa dalam suratnya ke Jingi. Tulus. Irewa menyayangi keduanya. Ia memang mencintai Meage. Tapi statusnya sebagai istri Malom tak bisa diubah lagi. Malom tetap adalah suaminya. Padahal Malom hanya senang-senang saja kerjanya. Saguer atau minum-minuman keras lain. Itulah dunianya. Juga perempuan muda. Golongan anak-anak yang lari dari orang tuanya. Tak mau menurut nasihat baik orang tua. Lebih ingin menuruti kesenangan sendiri semuanya. Anak-anak perempuan muda seperti itulah lingkaran Malom bergaul” (I:205).

\section{KESIMPULAN}

Berdasarkan hasil penelitian dan pembahasan maka dapat disimpulkan bahwa: Feminisme merupakan sebuah ideologi yang menitikberatkan pada persamaan hak antara perempuan dan laki-laki. Hal-hal yang dimunculkan dalam novel Isinga yaitu permasalahan perempuan yang dialami perempuan dan menentang kekerasan terhadap perempuan. Feminisme dalam novel ini lebih khusus kepada feminisme radikal; Permasalahan perempuan dalam novel Isinga adalah ketidakadilan dan kekerasan yang dialami, ketidakdilan yang dimaksudkan antara lain; ketidaksetaraan gender, kesenjangan sosial; dan sistem patriarki; Perjuangan tokoh perempuan dalam memerangi ketidakadilan yang ingin diungkapkan dalam novel ini yaitu perempuan yang tabah menghadapi kehidupan, perempuan yang mandiri dan perempuan yang berpikir maju. 


\section{DAFTAR PUSTAKA}

Herliany, D.R. 2015. Isinga Roman Papua. Jakarta: PT Gramedia.

Emzir \& Rohman, Saifur. 2015. Teori dan Pengajaran Sastra. Surabaya: Rajawali Pers. Afrizal. 2014. Metode Penelitian Kualitatif. Jakarta: PT Raja Grafindo Persada.

Sarwono, Jonathan. 2006. Metode Penelitian Kuantitatif \& Kualitatif. Yogjakarta: Graha Ilmu.

Strauss, A. Corbin, J. 2003. Dasar-dasar Penelitian Kualitatif.Terjemahan ole Muhamad Shodiq \& Imam Muttaqien. Yogjakarta: Pustaka Pelajar.

Brooks, Ann. 2009. Posefeminisme \& Cultural Studies.Terjemahan oleh S. Kunto Adi Wibowo.Yogjakarta: Jalasutra.

Moleong, J. 2010. Metodologi Penelitian Kualitatif. Bandung: PT Remaja Rosdakarya. 
Permasalahan Perempuan dalam Novel Isinga Karya Dorothea Rosa Herliany (Kajian Feminis) 